\title{
Glycerol production by the UV-mutant marine yeast Wickerhamomyces anomalus HH16-MU15 via simultaneous saccharification and fermentation of fruit peels
}

\author{
Abdel-Hamied M. Rasmey ${ }^{*}$ Heba Hawary, Akram A. Aboseidah, Mohamed H. Ahmed, El-Shahat \\ E. Khalaf
}

Botany and Microbiology Department, Faculty of Science, Suez University, Suez, Egypt.

\begin{tabular}{|c|c|}
\hline ARTICLE INFO & ABSTRACT \\
\hline $\begin{array}{l}\text { Article history: } \\
\text { Received } 6 \text { June } 2020 \\
\text { Received in revised form } 27 \text { June } 2020 \\
\text { Accepted } 28 \text { June } 2020 \\
\text { Available online } 29 \text { June } 2020\end{array}$ & $\begin{array}{l}\text { Agro-industrial wastes in Egypt are indefinite and sustainable substrate for production } \\
\text { of numerous industrially significant products. Using of these wastes as raw materials } \\
\text { can reduce both the production cost and the environmental pollution. The present } \\
\text { research aims to produce glycerol from fruit peels by the UV-mutant marine yeast } \\
\text { Wickerhamomyces anomalus HH16-MU15. Fruits (banana, orange, mango and }\end{array}$ \\
\hline $\begin{array}{l}\text { Keywords } \\
\text { Glycerol; } \\
\text { fruit peels; } \\
\text { hydrothermal treatment; } \\
\text { fermentation; } \\
\text { Wickerhamomyces anomalus. }\end{array}$ & $\begin{array}{l}\text { was obtained from mango peels followed by orange peels }\left(5.33 \pm 0.21 \mathrm{gl}^{-1}\right) \text { after their } \\
\text { hydrothermally pretreatment. After fermentation, the maximum cellulase activity }(8.911 \\
\left.\mathrm{Uml}^{-1}\right) \text {, total reducing sugars }\left(48.59 \mathrm{gl}^{-1}\right) \text { and glycerol yield }\left(35.25 \mathrm{gl}^{-1}\right) \text { by } W \text {. anomalus } \\
\mathrm{HH} 16-\mathrm{MU} 15 \text { were achieved in the hydrolysate of hydrothermally pretreated orange } \\
\text { peels at } 96 \mathrm{hrs} \text {. The current investigation suggests the using of orange peels for } \\
\text { production of glycerol and other valuable products by } W \text {. anomalus } \mathrm{HH} 16-\mathrm{MU} 15 \text {. }\end{array}$ \\
\hline
\end{tabular}

\section{Introduction}

Polyols (polyhydric alcohols) are sugar derivatives in which the aldo or keto group has been reduced to the corresponding hydroxyl group with the general formula $\mathrm{HOCH}_{2}(\mathrm{CHOH})_{n} \mathrm{CH}_{2} \mathrm{OH}$. They are one of the most abundant classes of organic molecules that have many biologically significant roles in marine yeasts [1]. Marine yeasts produce large amounts of polyols during their growth in their natural habitats to overcome the high external osmotic pressure of the marine environment [2]. It has been suggested that polyols may mimic the structure of water and maintain an artificial sphere of hydration around macromolecules preventing peroxidation of lipids that cause cell damage [3]. The most predominant polyol as an osmolyte in marine yeasts is the glycerol [4]. Glycerol (1,2,3-propanetriol) is used in manufacturing of food additives, cosmetics, paints, paper and leather as well as in the production of pharmaceutical formulating agents [5]. Moreover, it is a significant precursor for production of appreciated chemicals such as biodiesel, butanol, hydrogen, acrolein, citric acid, dichloro-2- propanol (DCP), 1,3-propanediol (1,3-PD), and 1,3-dihydroxyacetone (DHA) [1].

\footnotetext{
* Corresponding authors at: Suez University

E-mail addresses: am_rasmey@yahoo.com (Abdel-Hamied M. Rasmey)
}

Conversion of agro-industrial wastes such as fruit peels to glycerol can be an economic promising task. Furthermore, the use of seawater based medium for glycerol production could be a promising strategy for saving fresh water [6]. Fruit peels pose threat to the Egyptian environment by increasing the contamination and represent a loss of valuable biomass and nutrients. In the past years, the Egyptian fruit peels have been disposed in solid municipal wastes which cause environmental pollution and formation of unpleasant odors [7]. Currently, this is not economic since the presence of high amounts of nutrients (sugars, proteins, and fats) in these fruit residues [8]. Therefore, the treatment of these wastes and using them for production of glycerol instead of their disposal represents a sustainable eco-friendly alternative way. The fermentation of these wastes directly is very difficult and unsustainable because they have a complex structure of the three main components; cellulose, hemicellulose, and lignin with variable proportions [9]. They should be subjected to a pretreatment process in order to separate the celluloselignin complex proper to their fermentation by microorganisms [10].

Various mechanical, physical, chemical and biological processes can be used for agro-industrial wastes pretreatment [11-13]. Mechanical pretreatment is grinding step that usually performed to reduce the particle size crystallinity before subsequent processing steps. Physical pretreatment includes the hydrothermal pretreatment, also 
known as hot-compressed water treatment or autohydrolysis treatment, is an environmentally friendly technology at which biomass is treated with water at high temperature and pressure [14]. The second step in the bioconversion of fruit peels is the enzymatic hydrolysis of the physically or chemically pretreated waste. The biological conversion of lignocellulosic biomass to valuable products is mainly depend on the efficiency of enzymatic degradation of cellulose to reducing sugars [15]. Marine yeasts have gained considerable attention as a source of hydrolysis enzymes such as cellulase [16]. Therefore, simultaneous saccharification and fermentation (SSF) of fruit peels to glycerol by a marine yeast in single step will reduce the time and the overall cost of the process [17].

The current work was aimed to explore the capability of the mutant marine yeast Wickerhamomyces anomalus $\mathrm{HH} 16-\mathrm{HH} 5$ to utilize fruit peel hydrolysates as sustainable substrates for glycerol production. Moreover, this study has been evaluated the efficient pretreatment method (hydrothermal) for hydrolysis of fruit peels to release fermentable sugars and examined subsequent simultaneous saccharification and fermentation process.

\section{Materials and methods}

\section{Microorganism source:}

The yeast strain Wickerhamomyces anomalus $\mathrm{HH} 16$ MU5 used in the present study, is UV-mutant of the wild yeast $W$. anomalus $\mathrm{HH} 16$ which have been isolated from marine sediment, UV-treated and tested for glycerol production previously [5].

Preparation of yeast inocula:

A loopfull of $48 \mathrm{hrs}$ old yeast culture was inoculated into $50 \mathrm{ml}$ sterilized yeast extract-malt extract (YM) broth medium and then incubated for $48 \mathrm{hrs}$ on a rotary shaker (150 rpm) at $30{ }^{\circ} \mathrm{C}$. The YM broth medium consists of $(\mathrm{g} / \mathrm{l}$ seawater): yeast extract, 3.0; malt extract, 3.0; peptone, 5.0 and dextrose, 10.0 [13]. The medium $\mathrm{pH}$ was adjusted to $5.5 \pm 0.2$ using $0.1 \mathrm{~N} \mathrm{HCl}$ and $0.1 \mathrm{~N} \mathrm{NaOH}$.

\section{Fruit peels source:}

Different four types of fruit peels banana (Musa acuminate), orange (Citrus sinensis), mango (Mangifera indica) and pomegranate (Punica granatum) peels were collected from different natural juices shops located in Suez city, Egypt.

\section{Fruit peel hydrolysates preparation:}

\section{Mechanical pretreatment}

Fifty grams of each fruit peel (banana, orange, mango peels and pomegranate peel) was initially washed individually with tap water, air-dried for two hours and dried in a convection oven at $65^{\circ} \mathrm{C}$ for $24 \mathrm{hrs}$ [10]. The dried wastes were then milled using an electric mill to obtain particle size of approximately $1 \mathrm{~mm}$ in order to reduce the cellulose crystallinity to enhance the saccharification process (Figure 1).

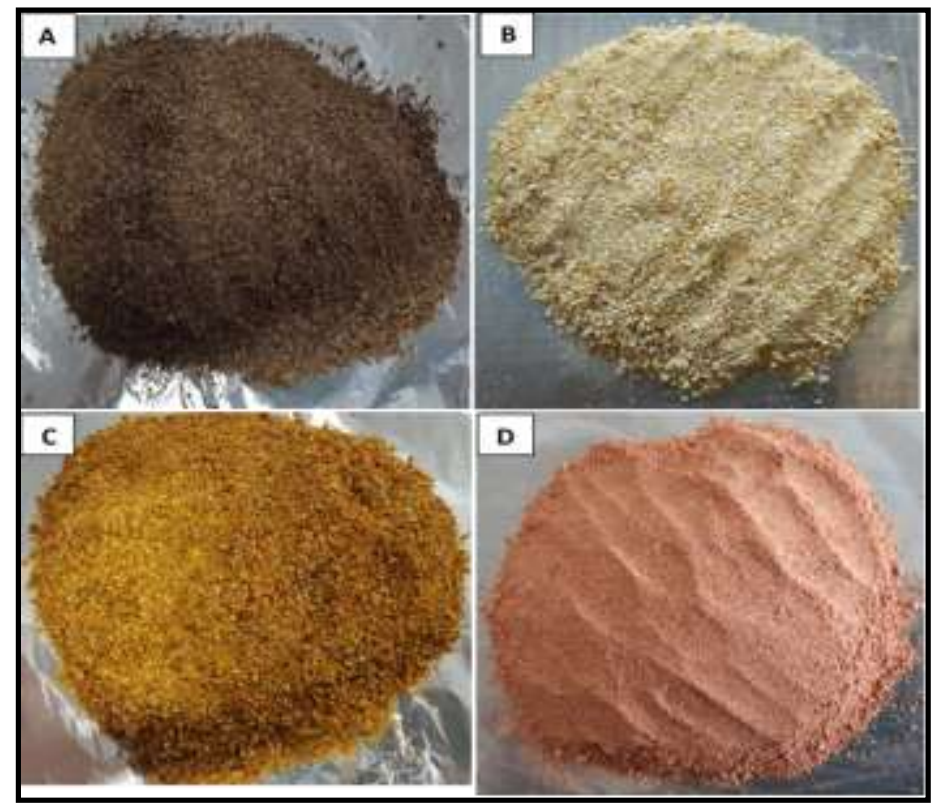

Fig 1: Shapes of grinded dry fruit peels after the mechanical pretreatment; a) banana peels, b) orange peels, c) mango peels and) pomegranate peels.

\section{Hydrothermal pretreatment:}

Fifty grams of each milled dry fruit peel was soaked in distilled water at a liquid to solid ratio of 1:20 (w/v) in 2 liters Erlenmeyer flask. The flasks were then autoclaved at $121{ }^{\circ} \mathrm{C}$ for 60 minutes. The residue was filtrated using cheese cloth and then dried in an oven at $65^{\circ} \mathrm{C}$ for one day [18].

Simultaneous saccharification and fermentation (SSF) process:

Simultaneous saccharification and fermentation (SSF) combines the enzymatic hydrolysis step and the fermentation step in order to make the conversion process more efficient. The used medium is composed of $\mathrm{gl}^{-1}$ seawater): yeast extract, 1 ; peptone, $1 ; \mathrm{KH}_{2} \mathrm{PO}_{4}, 1 ; \mathrm{MgSO}_{4}$, 0.5 and was supplemented with $50 \mathrm{~g}$ treated fruit peel. The medium $\mathrm{pH}$ was adjusted to $6.0 \pm 0.2$ using $0.1 \mathrm{~N} \mathrm{HCl}$ and $0.1 \mathrm{~N} \mathrm{NaOH}$.

The simultaneous saccharification and fermentation (SSF) process was conducted in $250 \mathrm{ml}$ Erlenmeyer flasks separately, each containing $100 \mathrm{ml}$ medium inoculated with $20 \%$ of the selected mutant yeast inocula $\left(10^{6}\right.$ cells $\left./ \mathrm{ml}\right)$. The flasks were incubated at on shaker incubator (150 rpm) at $30{ }^{\circ} \mathrm{C}$ and testing samples were taken at different fermentation periods $(24,48,72,96,120,144$ and 168 hrs). In each hydrolysate, the total reducing sugars, cellulase activity and glycerol were assayed as follows.

\section{Total reducing sugars (TRS) determination:}

The total reducing sugar liberated during the enzymatic assays was quantified by the dinitrosalicylic acid (DNS) method [19] using glucose as a standard. DNS reagent was prepared by dissolving $10.0 \mathrm{~g}$ of 3,5-dinitrosalicylic 
acid, $200 \mathrm{~g}$ of sodium potassium tartarate, $10.0 \mathrm{~g}$ of sodium hydroxide, $2.0 \mathrm{~g}$ of phenol and $0.5 \mathrm{~g}$ of sodium sulfite in one-liter distilled water. Three $\mathrm{ml}$ of diluted fermentation medium was added to $3 \mathrm{ml}$ of DNS reagent and the mixture was boiled for 5 minutes. The mixture was cooled down to room temperature, $1 \mathrm{ml}$ of Rochell salt $(40 \%$ potassium sodium tartarate) was then added and absorbance was measured at $510_{\mathrm{nm}}$ by UV-9200 VIS spectrophotometer.

Carboxymethyl cellulase (endo- $\beta-1,4$ glucanase) activity assay:

Carboxymethyl cellulase (endo- $\beta-1,4$ glucanase) activity was assayed by adding $0.5 \mathrm{ml}$ of the diluted hydrolysate to $0.5 \mathrm{ml}$ of $1 \%$ carboxymethyl cellulose solution and incubated for 30 minutes at $50{ }^{\circ} \mathrm{C}$. After incubation, $3 \mathrm{ml}$ of DNS reagent was added and boiled for 5 minutes. The absorbance was measured at $540 \mathrm{~nm}$ against the spectro zero by UV-9200 VIS spectrophotometer. The carboxymethyl cellulase (CMCase) enzymatic activity was assayed according to [20] using the following equation:

CMCase $=\frac{0.185}{\text { Enzyme concentration to release } 0.5 \mathrm{mg} \text { glucose }}$ units $\mathrm{ml}^{-1}$

All enzymatic assays were carried out in triplicate and the mean values were calculated and reported. For all activities, one unit of enzymatic activity $(U)$ was defined as the amount of enzyme that liberated $1 \mu \mathrm{mol}$ of the corresponding product (glucose equivalent) per minute, under the assay condition used.

\section{Glycerol determination:}

Glycerol was quantitatively measured using sodium periodate method according to [21]. For each experiment, total glycerol concentration $(P)$ and volumetric glycerol productivity $\left(Q_{p}\right)$ were calculated according to the following equation:

$$
Q_{p}=d P / d t
$$

Whereas volumetric glycerol productivity $\left(Q_{p}\right)$ was calculated as grams of glycerol formed per liter per hour $\left(\mathrm{gl}^{-1} \mathrm{~h}^{-1}\right)$.

\section{Result and Discussion}

3.1 Evaluation of the hydrothermal pretreatment process on fruit peels hydrolysis before the fermentation process:

Data presented in Figure 2 reveal that the hydrothermal pretreatment of grinded dry fruit peels can effectively afford the recovery of the reducing sugars from these wastes. [22] reported that the water-steam (hydrothermal) pretreatment is suitable efficient method for recovering the reducing sugars from fruit wastes. At hydrothermal pretreatment, pressure is gradually released, and the steam expands within the lignocellulosic complex, causing them to be separated, disrupted and simple sugars can be released in the hydrolysate [23]. In this study, the obtained maximum reducing sugars (5.792 $\left.\pm 0.16 \mathrm{gl}^{-1}\right)$ was resulted from hydrothermally pretreated mango peels, followed by orange peels with total reducing sugars $5.33 \pm$
$0.21 \mathrm{gl}^{-1}$. This result is consistent with [24], who investigated that among the four fruit wastes (banana, papaya, pineapple and mango peels), mango peels contain larger amounts of reducing sugars up to $40 \%(\mathrm{w} / \mathrm{v})$. This is might be attributed to the softens and low lignin content in the outside peels of mango fruits.

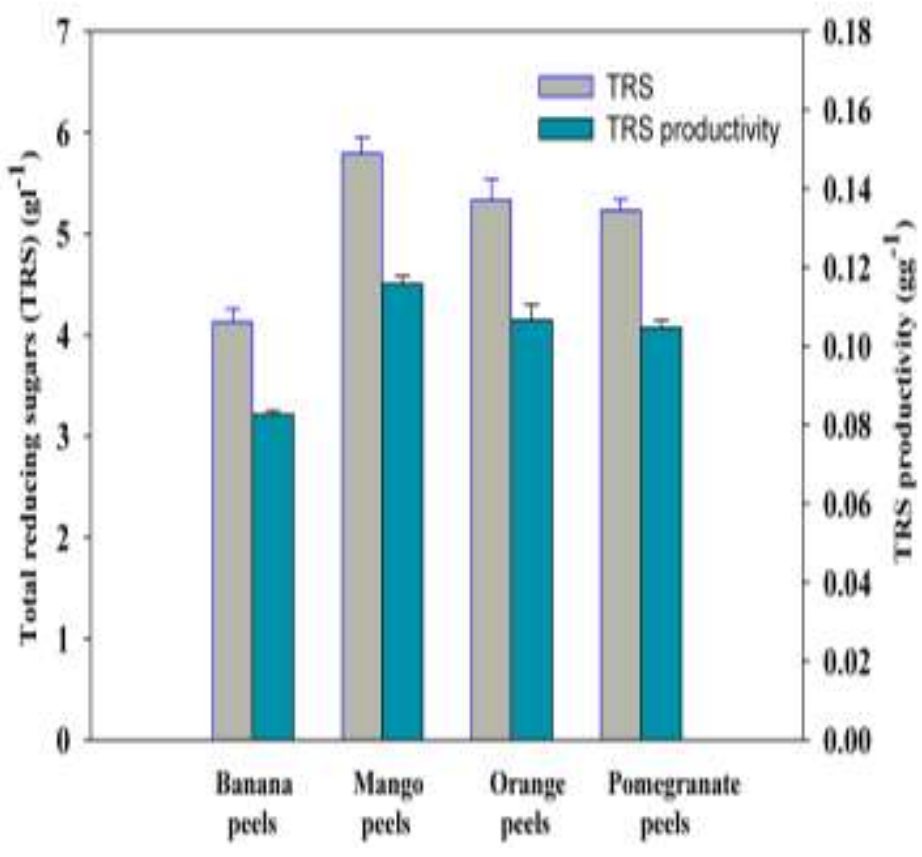

Fig 2: Total reducing sugars (TRS) and sugars productivity in the hydrolysates of the hydrothermally treated fruit peels before fermentation process.

3.2 Effect of the simultaneous saccharification and fermentation process on the total reducing sugars and carboxymethyl cellulase activity:

Data in Figure 3 reveal that simultaneous saccharification and fermentation of the different fruit peels using the mutant isolate $W$. anomalus HH16-MU5 resulted in suitable yields of total reducing sugars. However, statistical analysis of the results indicated that different fruit peels might exhibit various effects on the cellulase activity of the yeast and subsequently the liberated total reducing sugar. The maximum CMCase activity $8.911 \mathrm{Uml}^{-1}$ and the highest total reducing sugar $48.59 \mathrm{gl}^{-1}$ were recorded in the orange peels hydrolysate after 96 hrs of fermentation. On the other hand, the minimum CMCase activity $2.335 \mathrm{Uml}^{-1}$ was recorded after 168 hrs using the banana treated hydrolysate with the lowest reducing sugar recovery $13.159 \mathrm{gl}^{-1}$. The reason could be that the hydrolysis of various lignocellulosic materials release different mixture of hexose sugars (e.g. glucose, mannose), pentoses (e.g. xylose, arabinose) and inhibitors [25]. 


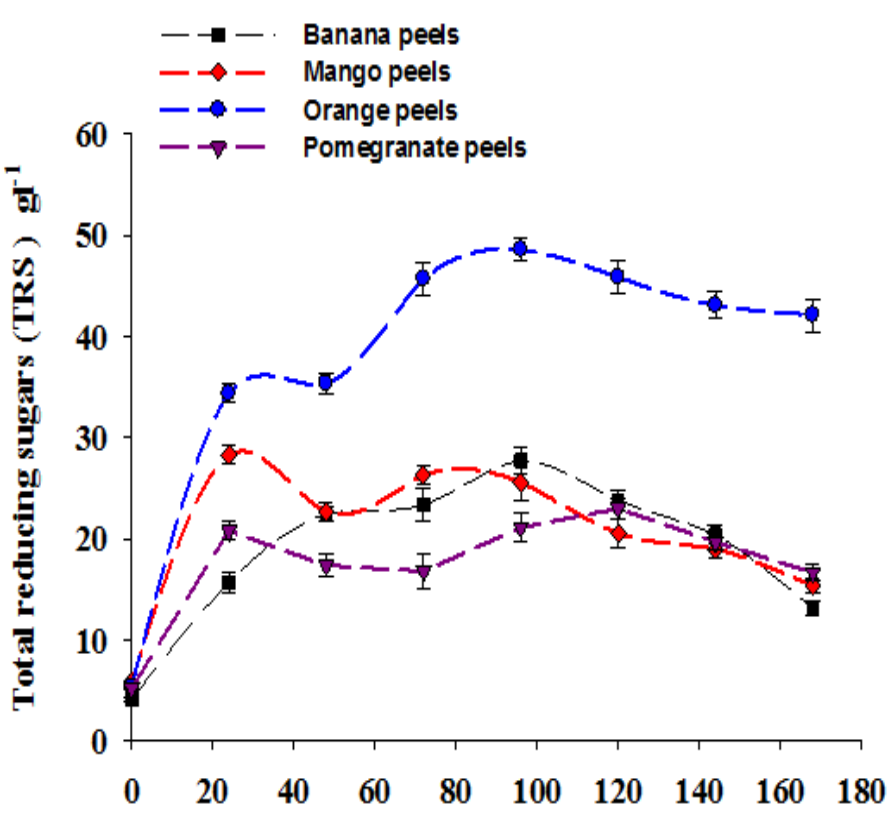

Fermentation time (hours)

Fig. 3: Total reducing sugars production during saccharification at different fermentation times using the mutant isolate $W$. anomalus $\mathrm{HH} 16-\mathrm{MU} 5$.

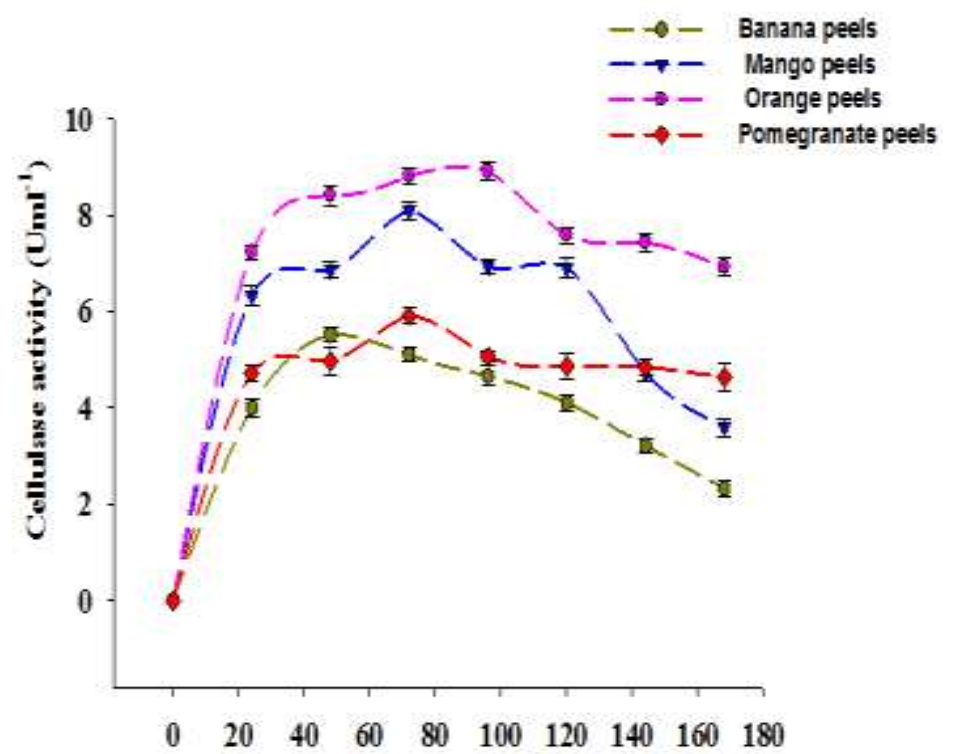

Fermentation time (hours)

Fig. 4: Carboxymethyl cellulase activity of the mutant isolate $W$. anomalus $\mathrm{HH} 16-\mathrm{MU} 5$ on the pretreated fruit peels at different fermentation times.
According to [26], steam explosion and liquid hot water pretreatments of fruit peels can generate soluble inhibitors which hamper the cellulase enzymatic activity and hence the released reducing sugars. Toxic and inhibitory compounds vary with the pretreatment method and the waste type that might include soluble sugars, organic acids (levulinic, acetic and formic acid), and furan derivatives (hydroxymethyl fulfural) $[9,27]$.

The obtained results in Figure 4 indicated that the mutant isolate $W$. anomalus $\mathrm{HH} 16-\mathrm{MU} 5$ has an efficient cellulase production system, therefore it could be a candidate for the enzymatic hydrolysis of lignocellulosic wastes that might reduce the time and the overall process cost. [17] reported that the simultaneous saccharification and fermentation using single yeast isolate can be considered as a cost-prohibitive due to the high cost of commercial cellulase enzymes. According to [28], cellulases isolated from marine fungi, especially yeast, have shown their potential for bioconversion processes which can have role in bioenergy-based industries. Several marine yeast genera such as Aureobasidium, Candida, Rhodotorula and Wickerhamomyces could be a source of cellulases and other valuable hydrolytic enzymes [5,29-30].

3.3 Glycerol production from fruit peels hydrolysates by W. anomalus HH16-MU5:

Results indicated that the simultaneous saccharification and fermentation of fruit peels to glycerol by the mutant marine yeast $W$. anomalus $\mathrm{HH} 16-\mathrm{MU} 15$ is sustainable and can be feasible. Moreover, the use of seawater-based medium can provide a huge impact on freshwater crisis especially in coastal areas where freshwater is priceless. There is a clear variation in the glycerol production by the mutant isolate $W$. anomalus $\mathrm{HH} 16 \mathrm{MU} 5$ at the different fruit peels hydrolysates (Figure 5). The maximum glycerol yield $35.25 \mathrm{gl}^{-1}$ was achieved with orange peels hydrolysate at $96 \mathrm{hrs}$ incubation at $30^{\circ} \mathrm{C}$ (Figure $5 \mathrm{C}$ ). This indicates the possibility of using orange peels as a promising substrate for glycerol production by yeast fermentation. In Egyptian citrus industries, the traditional re-use of orange peel and pulp wastes could be impractical and has a high cost, therefore peel and pulp wastes are accumulated in the soil by these industries that might cause serious environmental problems [31]. Orange peels could have the potential for valuable products as they are low cost with high renewable production rate [32].

The mango peels hydrolysate was the second best substrate for glycerol production with volumetric glycerol productivity $0.838 \mathrm{gl}^{-1} \mathrm{~h}^{-1}$ and glycerol production $31.67 \mathrm{gl}^{-1}$ after a fermentation times 24 and 96 hrs (Figure 5B). These results were in accordance to [24], who revealed that mango peels can be one of the potential and novel raw materials for yeast fermentation. 

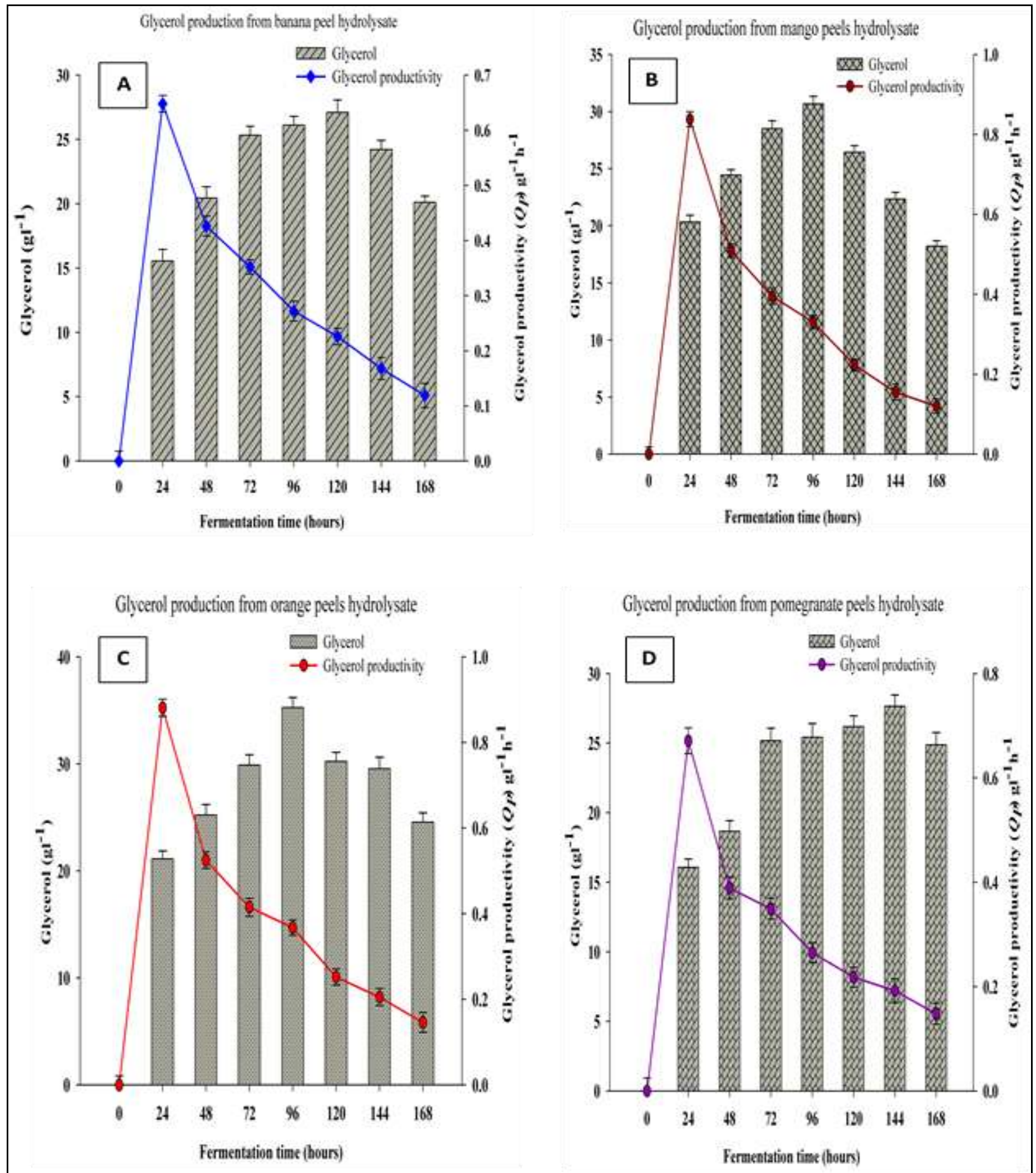

Fig. 5: Glycerol yields and glycerol productivity of the hydrothermally pretreated fruit peels at different fermentation times by the mutant isolate $W$. anomalus HH16-MU5. 
Although the banana peels hydrolysate showed a good sugar recovery (Figure 3 ), the recorded glycerol production rate was weak resulting in $27.11 \mathrm{gl}^{-1}$ glycerol after $120 \mathrm{hrs}$ (Figure 5A).This might be due to the phenolic acids, tannins and lignin that found in banana plant cell walls; the presence of phenolic and carboxyl groups can inhibit or decrease the fermentation efficiency [33].

\section{Conclusion}

The current investigation reveals that the UV-mutant marine yeast $W$. anomalus $\mathrm{HH} 16-\mathrm{MU} 15$ could be a candidate isolate for simultaneous saccharification and fermentation of the fruit peels to glycerol. Furthermore, the use of seawater based medium for glycerol production could be a promising strategy for saving fresh water. The hydrothermally pretreated orange peels can be good substrate for glycerol and cellulase production. The present study confirms that the efficiency of enzymatic hydrolysis and fermentation process is mainly depending on the pretreatment process and the type of agro-industrial waste.

\section{References}

1- Rasmey, A.M., Aboseidah, A.A, Khalaf, E.M., Ahmed, M.H., Hawary, H., 2020. Kinetic models application on glycerol production from glucose by the marine yeast Candida orthopsilosis. Egyptian Journal of Aquatic Biology and Fisheries 24(1), 1-12.

2- Connell, L., Redman, R., Craig, S., Scorzetti, G., Iszard, M., Rodriguez, R., 2008. Diversity of soil yeasts isolated from South Victoria Land, Antarctica. Microbial Ecology 56, 448-459.

3- Pereira, I., Madeira, A., Prista, C., Loureiro-Dias, M.C., Leandro, M.J., 2014. Characterization of new polyol/H+ simporters in Debaryomyces hansenii. PLos One 9(2), e88180.

4- Slama, I., Abdelly, C., Bouchereau, A., Flowers, T., Savouré, A., 2015. Diversity, distribution and roles of osmoprotective compounds accumulated in halophytes under abiotic stress. Annals of Botany 115(3), 433-447.

5- Hawary, H., Rasmey, A.H.M., Aboseidah, A. A., El-Morsi, E. S., Hafez, M., 2019. Enhancement of glycerol production by UVmutagenesis of the marine yeast Wickerhamomyces anomalus $\mathrm{HH} 16$ : kinetics and optimization of the fermentation process. 3 Biotech 9(12), 446.

6- Sarkar, A., Rao, K.V.B, 2016. Marine yeast: a potential candidate for biotechnological aplications- a review. Asian Journal of Microbiology, Biotechnology and Environmental Scienc es 18, 627-634.

7- Abd-Alla, M.H., Gabra, F.A., Danial, A.W., Abdel-Wahab, A.M., 2019. Enhancement of biohydrogen production from sustainable orange peel wastes using Enterobacter species isolated from domestic wastewater. International Journal of Energy Research 43, 391-404.

8- Sadh, P.K., Duhan, S., Duhan, J.S., 2018. Agro-industrial wastes and their utilization using solid state fermentation: a review. Bioresources and Bioprocessing 5(1), 1-15.

9- Kucharska, K., Rybarczyk, P., Hołowacz, I., Łukajtis, R., Glinka, M., Kamiński, M., 2018. Pretreatment of lignocellulosic materials as substrates for fermentation processes. Molecules 23(11), 2937-2969.
10- Rasmey, A.M., Hawary, H., Abo-Seidah, A.A., Wahid, O.A., 2017a. Chemical pretreatment and saccharification of sugarcane bagasse for bioethanol fermentation by Saccharomyces cerevisiae Y17-KP096551. Basic Research Journal of Microbiology 4(1), 1-11.

11- Beszédes, S., László, Z., Horváth, Z., Szabó, G., Hodúr, C., 2011. Comparison of the effects of microwave irradiation with different intensities on the biodegradability of sludge from the dairy and meat industry. Bioresource Technology 102(2), 814-21.

12- Rasmey, A.M., Basha, A.H., 2016. Isolation and screening of kojic acid producing isolate of Aspergillus oryzae potentially applicable for production from sugarcane molasses. International Journal of Biological Research 4(2), 119-128.

13- Rasmey, A.M., Aboseidah, A.A., Gaber, S., Mahran, F., 2017b. Characterization and optimization of lipase activity produced by Pseudomonas monteilli 2403-KY120354 isolated from ground beef. African Journal of Biotechnology 16(2), 96-105.

14- Lei, H.W., Cybulska, I., Julson, H., 2013. Hydrothermal pretreatment of lignocellulosic biomass and kinetics. Journal of Sustainable Bioenergy Systems 3, 250-259.

15- Yu, H., Guo, G., Zhang, X., Yan, K., Xu, C., 2009. The effect of biological pretreatment with the selective white-rot fungus Echinodontium taxodii on enzymatic hydrolysis of softwoods and hardwoods. Bioresource Technology 100, 5170-5175.

16- Zhang, L., Chi, Z.M., 2007. Screening and identification of a cellulase producing marine yeast and optimization of medium and cultivation conditions for cellulase production. Journal of Ocean University of China 37, 101-108.

17- Marulanda, V.A., Gutierrez, C.D.B., Alzate, C.A.C, 2019. Chapter 4: Thermochemical, biological, biochemical, and hybrid conversion methods of bio-derived molecules into renewable fuels. In: Hosseini, M. (Ed), Advanced bioprocessing for alternative fuels, biobased chemicals, and bioproducts. Wood head Publishing Series in Energy 59-81.

18- Chahande, A.D., Gedam, V.V., Raut, P.A., Moharkar, Y.P., 2018. Pretreatment and production of bioethanol from Citrus reticulata fruit waste with baker's yeast by solid-state and submerged fermentation. In: Ghosh S.K. (Ed), Utilization and management of bioresources, Department of Biotechnology, PIET, Nagpur, India.

19- Miller, G.L., 1959. Use of dinitrosalicylic acid reagent for determination of reducing sugar. Analytical Biochemistry 31, 426428.

20- Ghose, T. K., 1987. Measurement of cellulase activities. The International Union of Pure and Applied Chemistry. Pure and Applied Chemistry 59(2), 257-268.

21- Kuhn, J., Müller, H., Salzig, D., Czermak, P., 2015. A rapid method for an offline glycerol determination during microbial fermentation. Electronic Journal of Biotechnology 18(3), 252-255.

22- Jahid, M., Gupta, A., Sharma, D.K., 2018. Production of Bioethanol from Fruit Wates (Banana, Papaya, Pineapple and Mango Peels) Under Milder Conditions. Journal of Bioprocessing and Biotechniques 8(3), 327.

23- Agbor, V.B., Cicek, N., Sparling, R., Berlin, A., Levin, D.B., 2011. Biomass pretreatment: fundamentals toward application. Biotechnology Advances 29, 675-685.

24- Reddy, L.V., Reddy, O.V.S.R., Wee, Y.J, 2011. Production of ethanol from mango (Mangifera indica L.) peel by Saccharomyces 
cerevisiae CFTRI101. African Journal of Biotechnology 10(20), 4183-4189.

25- Chen, R., Wang, Y.Z., Liao, Q., Zhu, X., Xu, T.F., 2013. Hydrolysates of lignocellulosic materials for biohydrogen production. BMB Reports 46(5), 244-251.

26- Kim, Y., Ximenes, E., Mosier, N.S., Ladisch, M.R., 2011. Soluble inhibitors/deactivators of cellulase enzymes from lignocellulosic biomass. Enzyme and Microbial Technology 48 (5), 408-415.

27- Rasmey, A.M., Hassan, H.H., Abdulwahid, O.A., Aboseidah, A.A., 2018. Enhancing bioethanol production from sugarcane molasses by Saccharomyces cerevisiae Y17. Egyptian Journal of Botany 58(3), 547-561.

28- Trivedi, N., Reddy, C.R.K., Lali, A.M., 2016. Marine microbes as a potential source of cellulolytic enzymes, In: Kim, S., Toldrá, F. (Eds), Advances in food and nutrition research. Burlington: Academic Press 79, 27-41.

29- Yanjun, R., Liang, Z., Zhenming, C., Xianghong, W., 2015. A carboxymethyl cellulase from a marine yeast (Aureobasidium pullulans 98): its purification, characterization, gene cloning and carboxymethyl cellulose digestion. The Journal of Ocean University of China14, 913-921.

30- Dumorné, K., Severe, R., 2018. Marine enzymes and their industrial and biotechnological applications. Minerva Biotecnologica 30(4), 113-119.

31- Attyia, S.H., Ashour, S.M., 2002. Biodegradation of agroindustrial orange waste under solid state fermentation and natural environmental conditions. The Egyptian Journal of Experimental Biology 4, 23-30.

32- Santos, C.M., Dweck, J., Viotto, R.S., Rosa, A.H., de Morais, L.C., 2015. Application of orange peel waste in the production of solid biofuels and biosorbents. Bioresource Technology 196, 469479.

33- Saini, J.K., Saini, R., Tewari, L., 2015. Lignocellulosic agriculture wastes as biomass feedstocks for second-generation bioethanol production: concepts and recent developments. 3 Biotech 5(4), 337-353. 